\title{
Use of hybrid MCDM model in evaluation for cloud service application improvement

\author{
Min-Hsuan Yang ${ }^{1}$, Chiu-Hung Su ${ }^{2^{*}}$ and Wen-Cheng Wang ${ }^{3}$
}

\begin{abstract}
Cloud services represent an information revolution that is changing the computer usage habits of one billion people. The purposes for which consumers intend to use a cloud service must be identified and analyzed to guide providers in improving their software and enhancing its innovative and creative functions. Few studies have investigated methods for developing cloud service applications. Numerous key factors may be used to evaluate the application of cloud services. However, many standards rely on interactive features that are difficult to analyze. Therefore, the functions that cloud users consider in their choice of cloud services require further research and improvement. In this study, a hybrid multicriterion decision-making approach involving a decision-making trial and evaluation laboratory, a DEMATEL-based analytic network process, and VIKOR schemes was used to obtain optimal resolution. This study examines critical relationships among the rules that affect the cloud service application enterprise and potential sources of added value. The results of this study may serve as reference information for service providers. Additionally, the method demonstrated in this study can be utilized to resolve feedback issues among various factors and thereby facilitate more effective problem-solving and services in the cloud service application industry.
\end{abstract}

Keywords: Cloud service applications, DANP (DEMATEL-based analytic network process), MCDM (multiple criteria decision-making), VIKOR, INRM

\section{Introduction}

Cloud computing is not a single, novel technology but is instead a concept. "Simply put, the concept is to have all data processed online," said the General Manager for Google Taiwan. The "cloud" is actually a data center composed of several supercomputers with substantial computing power. "Accessing the cloud" refers to connecting to these supercomputers through the Internet, thereby allowing those computers to help the user process data. Previously, users had to pay for software, but with cloud computing, these users only need to purchase the services that are offered by a cloud provider, such as Amazon Elastic Compute Cloud (Amazon $\mathrm{EC}_{2}$ ) [1]. The absence of software or hardware platform costs provides users with substantial flexibility to adjust the resources that they allocate to services or servers [2]. The new concept is called as "Pay-as-you-go." These services are based on virtualization technologies, such as KVM or XEN. These

\footnotetext{
* Correspondence: ritasu@go.hwh.edu.tw

${ }^{2}$ Department of Electrical Engineering, Hwa Hsia University of Technology,

Taipei, Taiwan

Full list of author information is available at the end of the article
}

technologies obscure hardware and software characteristics from users. A number of different "clouds" already surround you. When you open your Gmail account, share photos at wretch.cc, Flickr, or download and upload various software and games on your iPhone, you are already using the cloud [3]. For example, when English users call German customers using smartphones, the mobile phone will translate the sounds into digital signals and transmit these signals to a cloud server for translation. The German customers will only hear the content of the call in German. Technology will substantially change the lives of individuals. When one feels lonely, one can chat with friends online using readily available devices. If one feels bored, one can fill one's time by searching for information or entertainment online. Therefore, few studies have explored the strategies through which companies producing a variety of cloud service applications can improve their cloud service applications. Lack of research impedes decision-makers from making information-based decisions and using innovative methods to improve the competitiveness of cloud-based service programs. 
In this study, our approach is to improve on or promote solutions to those problems. Our study employs an influential network diagram, which reveals performance gaps. Decision-makers can use this diagram to understand relationships among key factors and subsequently to propose reasonable strategies for improvement.

The purpose of this paper is to examine the management of key decisions based on the standards of corporate decision-makers. The present study employs the multiple criteria decision-making (MCDM) method to solve these real-life problems and evaluate the satisfaction of final customers. Through MCDM, the relevance of key factors and relationships among uses of cloud service applications in Taiwan are investigated. Finally, the results of this method indicate the ideal means for improvement.

The first step in the proposed process is to construct a comprehensive service evaluation relationship model. A decision-making trial and evaluation laboratory (DEMATEL) method is applied to construct an influential network relationship map (INRM), which is then manipulated to demonstrate the correlation between the influential network of determinants and the choice of cloud service applications. Subsequently, the DEMATELbased analytic network process (DANP) method is applied to arrange the weights of the criteria with regard to their level of influence. Further analysis of the criteria is then performed using VIKOR, which estimates the sizes of the discrepancy between actual and desired service delivery performance. The performance gaps are revealed in an INRM, which may aid decision-makers in understanding the relationships between service dimensions and criteria and enable them to propose effective strategies for improvement.

\section{Literature review}

The use of cloud service applications in the training systems of modern enterprises has become an important trend. The findings from the literature regarding perceptual characteristics, added characteristics, software characteristics, and external factors influence consumers' choice to adopt cloud service applications.

\subsection{Cloud service applications}

Software and services are the most commonly used cloud services and include websites such as Gmail, Google Docs, or Google Calendar. These data services are centrally hosted, and users can access the data with low-end devices because most of these data are processed by the host. Therefore, Salesforce.com and Google actively promote software as a service in cloud computing. Platforms that attract more users will also entice more developers to write cloud-based networking programs for relevant network platforms and to create an environment where cloud services can continue to be refined and applied to new challenges.

\subsection{Perceptual characteristics}

Chat room participants usually involved in discussions may form other trust and rely from their online friends [4]. Online cloud service software satisfies the need for a better online user experience. Individuals who enjoy online forums and electronic mailing list messages are attracted to chat rooms for guidance, information, entertainment, and social utility. Occasionally, the use of software is dependent on the potential difference between users' initial perceptions and expectations of the new technology and their actual use of this technology [5]. The directories in developed software are specific to individuals and professional environments. Because of cloud service applications, the mobile phone platform has become more than just a portable telephone; instead, it is a social artifact [6]. Mobile telephony is effect within the social relation by different attributes of owners' way of life [6, 7].

\subsection{Added characteristics}

Both companies that provide digital products and those that have established distribution channels other than the Internet can exploit their channels to provide aftersales services. From the business point of view, many products that have not yet started to sell carry potential added value, which will be determined through sales activities [8]. A product's core and peripheral services may be sources of added value. However, to an increasing extent, sources of added value, such as brand image, are driven by less practical factors in the market. Both awareness (recall and recognition) and image relate to brand associations that are held in the customer's memory [9]. Many consumers expected lower setup costs, lower costs from customer contact, and lower maintenance and use costs for virtual stores to establish that the perception of higher prices was associated with lower value [10].

\subsection{Software characteristics}

Perceived usefulness and ease of use are sensitive software characteristics [11-13]. Precise speed of movement is required for numerous types of human motion tasks. Ordinarily, when the speed of a motion increases, the accuracy of the movement decreases. This phenomenon has long been a consideration in the development of technology intended to perform tasks with both high speed and high accuracy [14]. The web was used to establish userfriendly and rich content, efficient interactive technology, and experimental learning in an online laboratory [15].

\section{Methodology}

The MCDM method can estimate multiple criteria simultaneously and can help decision-makers identify 
the most suitable decision plan among limited options. In this study, the DEMATEL approach was initially used to verify the effect of each rule and examine various relationships among service parameters. Subsequently, the DANP method, which is based on Saaty's theories and is a unique aggregate of the DEMATEL and ANP methods [17], was used to calculate the role of each of the key factors affecting the VIKOR method evaluation of cloud service application integrity.

\subsection{Evaluation criteria and data collection}

Three dimensions and 12 key factors were identified in the literature (see Table 1).

With regard to the data collection process, a survey featuring assessment criteria for cloud service applications was distributed among 30 experts in the cloud service application field. Data from interviews of these experts and the experts' surveys were combined for analysis. Sixteen of the experts were business leaders in cloud service applications. Eight of the experts used cloud services in government departments, and the remaining six were mainly cloud service application researchers. Survey items were scored on a 5-point scale. From April to July 2015, 30 surveys were distributed. After filling out the survey, each expert completed a 40-50-min interview.

\subsection{Use of DEMATEL technology to establish network relationships among the guidelines}

DEMATEL technology is often used to solve problems in MCDM. This proposed method in this study employs the DEMATEL approach to examine how the criteria of various systems indirectly and directly affect each other. Illustration of these effects may be helpful for developing a complete model for decision-making.

\subsection{Using the DANP method to determine the influence of weights}

In the proposed process, the DEMATEL method is used to confirm and compare the influences of the criteria. Subsequently, the DANP method is used to obtain the weights of these criteria [16]. The ANP, introduced by Saaty [17], mainly reduce the restrictions associated with the analytic hierarchy process (AHP) method to determine the relationship between nonlinear and complex networks in an attempt to build a solution. Ultimately, this research will combine DEMATEL technology ANP methods to resolve the dependency and feedback problems of the relationships between the guidelines $[18,19]$.

\subsection{Evaluating overall performance using the VIKOR method}

Opricovic and Tzeng developed VIKOR as a multicriterion decision-making method to solve the problem of noncontained and conflicting criteria [20-26]. In this study, the VIKOR method was used to assess the gap between the experts' evaluations and consumers' actual use of cloudbased application services. Expert opinion values were based on the efficiency scores of 0 to 10 that the experts indicated on their questionnaires. In application of the VIKOR method, 4 points indicated desired performance and 0 points indicated inferior performance. This method for establishing desired and inferior performance differs from traditional methods, but it has been applied to numerous challenges, such as smart phone improvement [27], e-store marketing [28], and RFID adoption [29].

\section{Empirical case study of cloud service applications}

This section focuses on the evaluation of the overall model of cloud service applications. Taiwan's cloud application services are analyzed as a case study, based on which strategies

Table 1 The dimensions and criteria associated with cloud service applications

\begin{tabular}{lll}
\hline Dimensions/origin & Criteria & Evaluated item \\
\hline Perceptual characteristics $\left(D_{1}\right)$ & Entertainment $\left(C_{11}\right)$ & The use of cloud computing for entertainment \\
& Socialization $\left(C_{12}\right)$ & The use and discussion of the cloud computing service by peers \\
& Information $\left(C_{13}\right)$ & The degree of individual information obtained by users \\
& Work $\left(C_{14}\right)$ & The use of cloud computing to increase work efficiency through data collection \\
Added characteristics $\left(D_{2}\right)$ & After-sales service $\left(C_{21}\right)$ & The after-sales service following the use of cloud computing \\
& Brand $\left(C_{22}\right)$ & The users' brand images of companies that provide cloud computing services \\
& Safety $\left(C_{23}\right)$ & The safety of using the cloud computing service. \\
& Costs $\left(C_{24}\right)$ & Cost of using cloud computing services \\
Software characteristics $\left(D_{3}\right)$ & Convenience and usefulness $\left(C_{31}\right)$ & Using cloud computing services is convenient and convenient \\
& Easy to use $\left(C_{32}\right)$ & Ease-of-use of cloud computing services \\
& High-speed computing $\left(C_{33}\right)$ & Availability of high-speed cloud computing services \\
& Rich content $\left(C_{34}\right)$ & The use of cloud computing is an aspect of obtaining rich content
\end{tabular}


for improvement are proposed. The preliminary investigation using the mixed MC DM method through the data collection of expert questionnaires is to use the decision model to provide the analysis results of the data.

\subsection{Research question}

Once the cloud computing era arrives, you will no longer need to carry a laptop around and you will not need to worry about broken or stolen computers because all of your data will be saved in the cloud. An account and password will be all that is needed to turn any available device with Internet capability, such as a mobile phone, a GPS, or the ATM on the street, into your firm's computer. The availability of cloud services will allow users to use production information from pharmaceutical companies and the lot numbers of their drugs to verify the authenticity of those drugs. This is one example of offering innovative cloud services. The next issue that arises after the applications and services to be implemented have been defined is how the service platform will be constructed. In addition to reviewing the feasibility of basic cloud computing, what needs and service attributes are important to users care? The security of cloud computing will become an increasingly important concern that merits consideration. The empirical portion of this paper seeks to demonstrate how enterprises develop user-demanded cloud computing services in an era when cloud computing is increasingly prevalent. This study assesses the feasibility and security of cloud applications and attempts to explain factors that affect user adoption of cloud service offerings. This analysis may help cloud service companies improve the quality of their services and cloud product brand messaging.

\subsection{Use of the DEMATEL method to establish a network diagram}

This study used the DEMATEL method and DNP to examine interfactor influences and structures of factors in decision-making problems and to analyze interactions among three latitudes and 11 criteria. Influence matrix $\mathrm{T}$ and degree of influence are sorted according to the domains of expert questionnaires. The average sample gap $\frac{1}{n^{2}} \sum_{i=1}^{n} \sum_{j=1}^{n}\left(\left|t_{i j}^{p}-t_{i j}^{p-1}\right| / t_{i j}^{p}\right) \times 100 \%=3.7 \%<5 \%$ was found to equal $3.7 \%$, which is less than the $5 \%$ maximum for significance. The confidence level was found to be $96.3 \%$, which surpasses the minimum $95 \%$ confidence indicator (see the comments in Table 2 for further details). These factors' effect within the medium-influence relationship matrix is illustrated in the INRM (Fig. 1).

Otherwise, we will avoid discovering a cure for the problem and will instead merely treat its symptoms. We need to systematically solve the problem. We should not just solve the problem, but we need to find out the root cause of the problem.

We used the DEMATEL method to compare pairs of dimensions with criteria to establish and manipulate the network diagram and illustrate relational influences. These results may help determine priorities for software improvement.

As shown in Fig. 1 and Table 3, three dimensions influence each other. For example, the perceptual characteristics $\left(D_{1}\right)$ dimension affects the software characteristics $\left(D_{3}\right)$ dimension, and the added characteristics $\left(D_{2}\right)$ dimension $\left(D_{1} \rightarrow D_{3} \rightarrow D_{2}\right)$; the Software characteristics $\left(D_{3}\right)$ dimension affects the Added characteristics $\left(D_{2}\right)$ dimension $\left(D_{3} \rightarrow D_{2}\right)$.

Table 2 Total influential effect matrix $T_{c}$ of criteria

\begin{tabular}{|c|c|c|c|c|c|c|c|c|c|c|c|c|}
\hline$T_{c}$ & $C_{11}$ & $C_{12}$ & $C_{13}$ & $C_{14}$ & $C_{21}$ & $C_{22}$ & $C_{23}$ & $C_{24}$ & $C_{31}$ & $C_{32}$ & $C_{33}$ & $C_{34}$ \\
\hline$C_{11}$ & 0.118 & 0.127 & 0.171 & 0.094 & 0.121 & 0.093 & 0.127 & 0.233 & 0.088 & 0.172 & 0.124 & 0.123 \\
\hline$C_{12}$ & 0.307 & 0.137 & 0.214 & 0.219 & 0.136 & 0.220 & 0.301 & 0.307 & 0.212 & 0.216 & 0.305 & 0.140 \\
\hline$C_{13}$ & 0.286 & 0.246 & 0.183 & 0.213 & 0.247 & 0.213 & 0.296 & 0.296 & 0.210 & 0.196 & 0.300 & 0.245 \\
\hline$C_{14}$ & 0.307 & 0.172 & 0.239 & 0.118 & 0.169 & 0.130 & 0.310 & 0.317 & 0.123 & 0.231 & 0.303 & 0.176 \\
\hline$C_{21}$ & 0.305 & 0.154 & 0.218 & 0.222 & 0.137 & 0.226 & 0.310 & 0.307 & 0.208 & 0.217 & 0.311 & 0.147 \\
\hline$C_{22}$ & 0.310 & 0.176 & 0.247 & 0.121 & 0.172 & 0.123 & 0.321 & 0.327 & 0.131 & 0.238 & 0.312 & 0.178 \\
\hline$C_{23}$ & 0.133 & 0.116 & 0.167 & 0.084 & 0.119 & 0.082 & 0.111 & 0.224 & 0.077 & 0.166 & 0.119 & 0.119 \\
\hline$C_{24}$ & 0.223 & 0.200 & 0.255 & 0.166 & 0.199 & 0.165 & 0.228 & 0.201 & 0.159 & 0.255 & 0.228 & 0.200 \\
\hline$C_{31}$ & 0.322 & 0.182 & 0.247 & 0.145 & 0.181 & 0.146 & 0.329 & 0.337 & 0.120 & 0.247 & 0.330 & 0.179 \\
\hline$C_{32}$ & 0.289 & 0.234 & 0.182 & 0.206 & 0.222 & 0.209 & 0.288 & 0.276 & 0.201 & 0.176 & 0.288 & 0.239 \\
\hline$C_{33}$ & 0.129 & 0.129 & 0.173 & 0.092 & 0.133 & 0.110 & 0.127 & 0.237 & 0.093 & 0.174 & 0.126 & 0.131 \\
\hline$C_{34}$ & 0.311 & 0.146 & 0.219 & 0.223 & 0.145 & 0.226 & 0.312 & 0.312 & 0.219 & 0.225 & 0.313 & 0.141 \\
\hline
\end{tabular}

Note: $\frac{1}{n^{2}} \sum_{i=1}^{n} \sum_{j=1}^{n} \frac{\left|t_{i j}^{p}-t_{i j}^{-1}\right|}{t^{p}} \times 100 \%=3.7 \%<5 \%$, where $t_{i j}^{p}$ and $t_{i j}^{p-1}$ represent the average influence of the samples $p$ and $p-1$ on the criteria and $n$ represents the number of criteria. The results shown in Table 2 reach 97\%, which is greater than the 95\% required for significance 


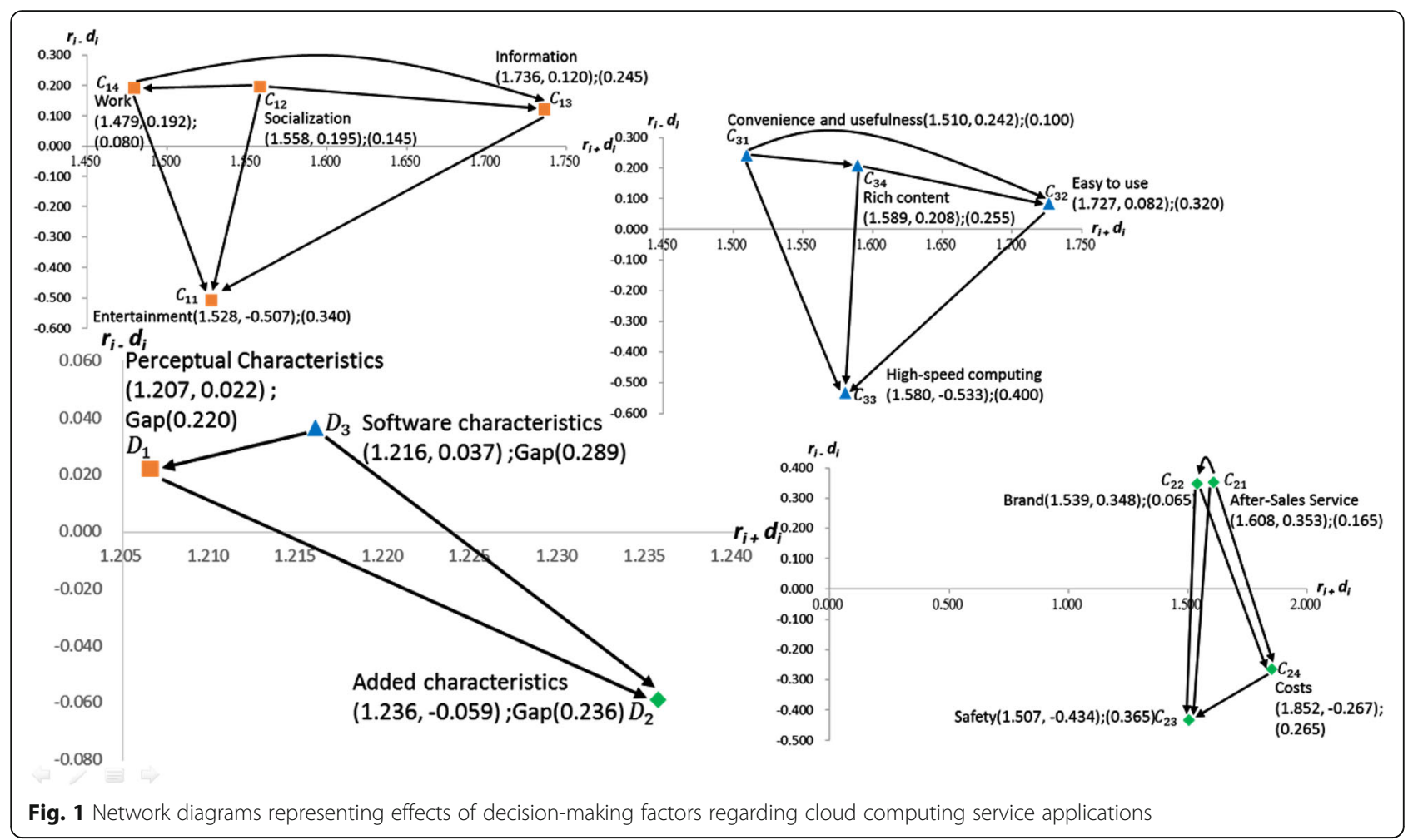

The network diagram illustrates the strength and direction of influence among the guidelines; that is, $r_{i}+d_{i}$ (influential network relation map (INRM)) indicates the influence that each dimension and criterion has. If it is positive, each dimension and criterion interact with each other factors. If it is negative, every dimension and criterion will be affected by other factors. Figure 1 shows the effect of this mutual influence.

Table 3 Weighted influence of each criterion

\begin{tabular}{lllll}
\hline Dimensions/criteria & $r_{\mathrm{i}}$ & $d_{\mathrm{i}}$ & $r_{\mathrm{i}}+d_{\mathrm{i}}$ & $r_{\mathrm{i}}-d_{\mathrm{i}}$ \\
\hline Perceptual characteristics $\left(D_{1}\right)$ & 0.614 & 0.592 & 1.207 & 0.022 \\
Entertainment $\left(C_{11}\right)$ & 0.511 & 1.017 & 1.528 & -0.507 \\
Socialization $\left(C_{12}\right)$ & 0.877 & 0.682 & 1.558 & 0.195 \\
Information $\left(C_{13}\right)$ & 0.928 & 0.808 & 1.736 & 0.120 \\
Work $\left(C_{14}\right)$ & 0.835 & 0.644 & 1.479 & 0.192 \\
Added characteristics $\left(D_{2}\right)$ & 0.588 & 0.647 & 1.236 & -0.059 \\
After-sales service $\left(C_{21}\right)$ & 0.980 & 0.628 & 1.608 & 0.353 \\
Brand $\left(C_{22}\right)$ & 0.943 & 0.596 & 1.539 & 0.348 \\
Safety $\left(C_{23}\right)$ & 0.537 & 0.970 & 1.507 & -0.434 \\
Costs $\left(C_{24}\right)$ & 0.793 & 1.059 & 1.852 & -0.267 \\
Software characteristics $\left(D_{3}\right)$ & 0.626 & 0.590 & 1.216 & 0.037 \\
Convenience and usefulness $\left(C_{31}\right)$ & 0.876 & 0.634 & 1.510 & 0.242 \\
Easy to use $\left(C_{32}\right)$ & 0.905 & 0.822 & 1.727 & 0.082 \\
High-speed computing $\left(C_{33}\right)$ & 0.524 & 1.057 & 1.580 & -0.533 \\
Rich content $\left(C_{34}\right)$ & 0.899 & 0.690 & 1.589 & 0.208 \\
\hline
\end{tabular}

The relationships between the affected latitudes will also be found in the relational network diagrams. In general, the perceptual characteristics $\left(D_{1}\right)$, added characteristics $\left(D_{2}\right)$, and software characteristics $\left(D_{3}\right)$ dimensions are the most influential criteria for work, branding, and enrichment. Because each of these dimensions has the greatest impact on other dimensions. For instance, within perceptual characteristics $\left(D_{1}\right)$, a direct impact on other criteria in the work $\left(C_{14}\right)$ guidelines, including entertainment $\left(C_{11}\right)$, socialization $\left(C_{12}\right)$, and information $\left(C_{13}\right)$, as users occasionally employ cloud service applications for daily activities, such as using word processing software, using chat software, obtaining research information, or writing a report, among others.

This effect shows that it is important for expert users to consider the use of cloud-based services and excellent software characteristics, directly affects the work choices of users, and is the most influential way to improve cloud service applications. By contrast, the guidelines for entertainment were found to be influenced by other criteria and should therefore be the last priority for improvement due to the relevance of cloud service applications for other uses. Developers should enhance the problem-solving functions of these applications and ensure the effectiveness of cloud computing service programs. These improvements will make users feel that the cloud service applications meet their needs and are reliable and effective tools. 
4.3 Use of the DANP method to calculate criteria weight The intercriteria influences were confirmed using the DEMATEL method. Subsequently, the DANP method was used to calculate the weight of the criteria. Pairs of unsupervised and weighted criteria were compared within a supermatrix, and the limit capability of the weighted supermatrix was determined to be stable. The weight of each criterion (Table 4) was then further analyzed using the VIKOR method.

\subsection{Application of the VIKOR method to evaluate guideline efficacy}

Use the DANP score combined with VIKOR method to calculate the overall performance of cloud services, as shown in Table 4; using this method, high-to-low gap values may be determined. Priority for improvement should then be assigned from low-to-high gap values to achieve the desired level of performance.

For example, the perceived performance dimension $\left(D_{1}\right)$ shows the highest performance at 7.801 and the lowest gap value at 0.220 . These measurements represent the most satisfying (and satisfactory) dimensions. Contrastingly, the results for software characteristics $\left(D_{3}\right)$ indicate that it is the most unsatisfactory latitude. Software characteristics score the lowest performance and the largest gap value; thus, the highest priority should be given to its improvement. Thus, to achieve the desired software performance level, decision-makers should prioritize $\left(D_{3}\right)$ improvements, followed by $D_{1}$ and finally $D_{2}$. The average benefit from using cloud services is 7.52 . The average gap between actual performance and desired performance is 0.248 , indicating that many challenges remain to be addressed in further development of cloud service applications.

This evaluation process can be applied to every latitude. For example, in the perception feature dimension $\left(D_{1}\right)$, the performance value of work standards was found to be up to 9.200 , and the minimum gap was found to be 0.080 . The entertainment criterion was found to have the lowest performance value (6.600) and the largest gap value (0.340). Because one criterion may influence all the factors, improvements of the criteria in this dimension should be continued. Information from software services should also be collected for application in improvements to operational efficiency. Further research discussions should be held with same-industry companies that use cloud software. The terms of service and the use of cloud software service for entertainment purposes should specifically be discussed. The results of this study indicate that the minimum performance value for entertainment standards is 6.600 , and the minimum gap value is 0.340 ; therefore, work appears to be the first criterion within this dimension that must be improved that will in turn affect the entertainment criterion to reduce their gaps to the desired level. Therefore, regarding the cloud service applications examined in this study, the use of software services to collect information to enhance operational efficiency and the discussion of software service usage by peers are the criteria that must be satisfied to obtain optimal performance in cloud service applications that will increase user

Table 4 Evaluation of the research performance of the VIKOR method

\begin{tabular}{|c|c|c|c|c|}
\hline Dimension/criteria & Local weight (based on DANP) & Global weight (based on DANP) & Performance & GAP \\
\hline Perceptual characteristics $\left(D_{1}\right)$ & 0.324 & & 7.801 & 0.220 \\
\hline Entertainment $\left(C_{11}\right)$ & 0.303 & 0.098 & 6.600 & 0.340 \\
\hline Socialization $\left(C_{12}\right)$ & 0.223 & 0.072 & 8.550 & 0.145 \\
\hline Information $\left(C_{13}\right)$ & 0.283 & 0.092 & 7.550 & 0.245 \\
\hline Work $\left(C_{14}\right)$ & 0.191 & 0.062 & 9.200 & 0.080 \\
\hline Added characteristics $\left(D_{2}\right)$ & 0.353 & & 7.635 & 0.236 \\
\hline After-sales service $\left(C_{21}\right)$ & 0.203 & 0.072 & 8.350 & 0.165 \\
\hline Brand $\left(C_{22}\right)$ & 0.180 & 0.064 & 9.350 & 0.065 \\
\hline Safety $\left(C_{23}\right)$ & 0.278 & 0.098 & 6.350 & 0.365 \\
\hline Costs $\left(C_{24}\right)$ & 0.339 & 0.120 & 7.350 & 0.265 \\
\hline Software characteristics $\left(D_{3}\right)$ & 0.323 & & 7.111 & 0.289 \\
\hline Convenience and usefulness $\left(C_{31}\right)$ & 0.186 & 0.060 & 9.000 & 0.100 \\
\hline Easy to use $\left(C_{32}\right)$ & 0.284 & 0.092 & 6.800 & 0.320 \\
\hline High-speed computing $\left(C_{33}\right)$ & 0.305 & 0.098 & 6.000 & 0.400 \\
\hline Rich content $\left(C_{34}\right)$ & 0.225 & 0.073 & 7.450 & 0.255 \\
\hline Total performance & & & 7.520 & \\
\hline Total gap & & & & 0.248 \\
\hline
\end{tabular}


satisfaction. However, customers of cloud service applications are the least satisfied with the abilities of employees to solve problems quickly by providing accurate information and assistance.

\subsection{Discussion and influence}

The results of DEMATEL technology can provide unique management insights. DEMATEL analysis may be used to evaluate the performance of cloud services relative to other standards, and these comparisons may enable decision-makers to improve cloud service products. In this empirical investigation, an INRM (Fig. 1) was used to calculate and explain the scope and criteria of influencing factors. Factors' degrees of influence are listed in Fig. 1. These values were used to designate improvement priority among the various dimensions. Improvement priority was determined from highest to lowest as follows: perceptual characteristics $\left(D_{1}\right)$, added characteristics $\left(D_{2}\right)$, and software characteristics $\left(D_{3}\right)$. The priority level of software characteristics $\left(D_{3}\right)$ is a critical indicator for decision-makers. According to the views of the experts, the perception characteristics dimension should be considered the highest priority, because improvements in this dimension will define a cloud service's brand. This dimension contributes to users' task-related benefits, thereby influencing the software characteristics aspect of cloud service applications. This finding verifies the general perceptual characteristics, added characteristics, and software characteristics and is consistent with the general results of previous studies [23]. The INRM introduced in this study enables in-depth analysis based on representation of influential relationships within a system (as shown in Fig. 1).

Web-based searches can be performed to identify software-oriented users and their needs. Improvements can then be made to increase the satisfaction of these users and improve the ease of use of software applications. The primary task for improving cloud-based service application development is to make the software more accessible and effective for its users, who generally seek convenience, usefulness, and ease of use. In addition, this study finds that increasing the security of cloud service applications is the most influential determinant for the added characteristics dimension. Therefore, the developers of cloud service applications should design application processes that provide rapid, task-oriented, and high-speed computing with rich information content and easy-to-use delivery policies; these processes should address areas relevant to users, such as the problem-solving abilities, behaviors, and preferences of consumers.

The overall performance indicators presented in Table 4 show that the average actual benefit of using cloud service applications is 7.520 compared with the expected level of 10 , and the average gap 0.248 is comparable to the required level of 0 . The software characteristics dimension $\left(D_{3}\right)$ for which a maximum gap of 0.289 was found. Therefore, the software characteristics dimension should be the priority performance level for improvement. In addition, the results indicate that the quality of performance is a critical factor in the overall improvement of cloud service applications. According to these empirical research results, consumers' main considerations when choosing cloud service applications are software characteristics, the software's ease-of-use, the desire for high-speed computing capability, and the discussion of these services by peers.

\section{Conclusions}

Cloud service applications play an important role in companies. Decisions related to these applications are complex because standard criteria have not been determined and criteria may differ among platforms due to complex output categories and usage conditions. Not only the most challenging problems must be identified but also the means through which the gap between desired and actual performance can be bridged and innovation and creativity in cloud service application development can be furthered must be found. In this comparison, the evaluation of the cloud service applications that are impacted by experts in the field yielded useful results. The order of effectiveness was improved from the largest to the smallest, and the priorities were improved as follows: software characteristics, additional characteristics, and perception characteristics. The average gap between the actual level and the desired level of the cloud application service is 0.248 . This indicates that there are deficiencies in the current cloud service and must be resolved.

New digital platforms should focus on the criteria identified in this study to achieve performance goals. Communication interfaces should be designed to meet the needs of the average consumer (e.g., family functions) and to meet users' expectations for performance. $R \& D$ design efforts for cloud service applications, which should include both user-friendly material and reasonable prices, should move towards a model that emphasizes after-sales services and entertainment. Highlighting the interesting uses of colorful multimedia to make application interfaces livelier can allow the user to personalize those interfaces and thereby increase user-interface interactions. For the empirical application of our approach, this study examines cloud service application use in Taiwan. Applied to Taiwan's situation, the proposed method proved effective in solving complex challenges related to cloud service applications, and the results may contribute to decision-making and further innovation. The researchers involved in the present study hope that the findings presented herein will increase the efficiency of resource utilization and contribute to improvements in the quality of cloud service applications. 


\section{Abbreviation}

AHP: Analytic hierarchy process; ANP: Analytic network process: ATM: Automated teller machine; DANP: DEMATEL-based analytic network process; GPS: Global positioning system; INRM: Influential network relation map; MCDM: Multiple criteria decision-making; RFID: Radio-frequency identification; VIKOR: VIseKriterijumska Optimizacija I Kompromisno Resenje

\section{Funding}

This research work is funded by authors themselves.

\section{Authors' contributions}

All authors have contributed jointly to all parts throughout the preparation of this manuscript, and all authors have read and approved the final manuscript.

\section{Competing interests}

The authors declare that they have no competing interests.

\section{Publisher's Note}

Springer Nature remains neutral with regard to jurisdictional claims in published maps and institutional affiliations.

\section{Author details}

'Department of Business Administration, National Taiwan University of Science and Technology, Taipei, Taiwan. ${ }^{2}$ Department of Electrical Engineering, Hwa Hsia University of Technology, Taipei, Taiwan. ${ }^{3}$ Department of Business Administration, Hwa Hsia University of Technology, Taipei, Taiwan.

\section{Received: 19 March 2018 Accepted: 18 April 2018}

Published online: 02 May 2018

\section{References}

1. A Gutierrez, E Boukrami, R Lumsden, Technological, organisational and environmental factors influencing managers decision to adopt cloud computing in the UK. J. Enterp. Inf. Manag. 28(6), 788-807 (2015)

2. J Li, J Huai, C Hu, Y Zhu, A secure collaboration service for dynamic virtual organizations. Inf. Sci. 180(17), 3086-3107 (2010)

3. J Li, Y Jia, L Liu, T Wo, CyberLiveApp: a secure sharing and migration approach for live virtual desktop applications in a cloud environment. Futur. Gener. Comput. Syst. 29(1), 330-340 (2013)

4. R Rauniar, G Rawski, J Yang, B Johnson, Technology acceptance mode (TAM) and social media usage: an empirical study on Facebook. J. Enterp. Inf. Manag. 27(1), 6-30 (2014)

5. XL Shen, N Wang, Y Sun, L Xiang, Unleash the power of mobile word-ofmouth: an empirical study of system and information characteristics in ubiquitous decision making. Online Inf. Rev. 37(1), 42-60 (2013)

6. ST Shen, People and their smartphones-mapping mobile interaction in the modern connected world. Eng. Comput. 33(6), 1642-1658 (2016)

7. V Magrath, H McCormick, Marketing design elements of mobile fashion retail apps. J Fash Mark Manage Int J 17(1), 115-134 (2013)

8. K Tollin, M Schmidt, Marketing's contribution from the perspective of marketing executives. Mark. Intell. Plan. 33(7), 1047-1070 (2015)

9. JJ Hew, VH Lee, KB Ooi, B Lin, Mobile social commerce: the booster for brand loyalty? Comput. Hum. Behav. 59, 142-154 (2016)

10. M Walterbusch, B Martens, F Teuteberg, Evaluating cloud computing services from a total cost of ownership perspective. Manage Res Rev 36(6), 613-638 (2013)

11. KY Lin, User communication behavior in mobile communication software. Online Inf. Rev. 40(7), 1071-1089 (2016)

12. W Nuwan, P Kasun, S Manoj, B Brenda, S Tichafara, Useful and easy-to-use interactive voice for emergency data exchange, info. 15(5), 82-98 (2013)

13. J Lindoval Aragão Matos, RP Lourenço, Use and acceptance of social software in corporate environments. Manag Res: I Iberoamerican Acad Manag 11(3), 305-329 (2013)

14. XL Zhou, XS Ren, Speed-accuracy tradeoff models of target-based and trajectory-based movements. Int J Innov Comput Inform Control 5(12), 4441-4451 (2009)

15. MN Islam, F Tétard, Exploring the impact of interface signs' interpretation accuracy, design, and evaluation on web usability: a semiotics perspective. J Syst Inform Technol 16(4), 250-276 (2014)
16. FH Chen, GH Tzeng, TS Hsu, A balanced scorecard approach to establish a performance evaluation and relationship model for hot spring hotels based on a hybrid MCDM model combining DEMATEL and ANP. Int. J. Hosp. Manag. 30, 908-932 (2011)

17. Saaty T L. Decision making with dependence and feedback: the analytic network process, PA:RWS Publications, Pittsburgh, 1996.

18. CH Liu, GH Tzeng, MH Lee, Improving tourism policy implementation-the use of hybrid MCDM models. Tour. Manag. 33(2), 413-426 (2012)

19. WY Chiu, GH Tzeng, HL Li, Developing e-store marketing strategies to satisfy customers' needs using a new hybrid gray relational model. Int J Inform Technol Decis Mak 13(2), 231-261 (2014)

20. CH Liu, GH Tzeng, MH Lee, PY Lee, Improving metro-airport connection service for tourism development: using hybrid MCDM models. Tour Manag Perspect 6, 95-107 (2013)

21. JJ Huang, $\mathrm{CY}$ Chen, $\mathrm{HH}$ Liu, GH Tzeng, A multi-objective programming model for partner selection-perspectives of objective synergies and resource allocations. Expert Syst. Appl. 37(5), 3530-3536 (2010)

22. S Opricovic, GH Tzeng, Compromise solution by MCDM methods: a comparative analysis of VIKOR and TOPSIS. Eur. J. Oper. Res. 156, 445-455 (2004)

23. S Opricovic, GH Tzeng, Fuzzy multicriteria model for post-earthquake landuse planning. Nat Hazards Rev 4, 59-64 (2004)

24. S Opricovic, GH Tzeng, Multicriteria planning of post-earthquake sustainable reconstruction. Comput Aided Civil Infrastruct Eng 17, 211-220 (2002)

25. YP Ou Yang, HM Shieh, JD Leu, GH Tzeng, A VIKOR-based multiple criteria decision method for improving information security risk. Int J Inf Technol Decis Making 8(2), 267-287 (2009)

26. YP Ou Yang, HM Shieh, JD Leu, GH Tzeng, A novel hybrid MCDM model combined with DEMATEL and ANP with applications. Int J Oper Res 5(3), 160-168 (2008) 2008

27. SK Hu, MT Lu, GH Tzeng, Exploring smart phone improvements based on a hybrid MCDM model. Expert Syst. Appl. 41(9), 4401-4413 (2014)

28. JL Yang, GH Tzeng, An integrated MCDM technique combined with DEMATEL for a novel cluster-weighted with ANP method. Expert Sys. Appl. 38, 1417-1424 (2011)

29. MT Lu, SW Lin, GH Tzeng, Improving RFID adoption in Taiwan's healthcare industry based on a DEMATEL technique with a hybrid MCDM model. Decis. Support. Syst. 56, 259-269 (2013)

\section{Submit your manuscript to a SpringerOpen ${ }^{\circ}$ journal and benefit from:}

- Convenient online submission

Rigorous peer review

- Open access: articles freely available online

- High visibility within the field

- Retaining the copyright to your article

Submit your next manuscript at $>$ springeropen.com 